\title{
VASOPRESSIN SERUM LEVELS IN PATIENTS WITH SEVERE BRAIN LESIONS AND IN BRAIN-DEAD PATIENTS
}

\author{
Eliane de Araújo Cintra ${ }^{1}$, Jayme Antunes Maciel Jr², Sebastião Araújo3, \\ Margaret de Castro ${ }^{4}$, Edna Freitas Martins ${ }^{5}$, Antônio Luiz Eiras Falcão ${ }^{3}$, \\ Luiz A.C. Sardinha ${ }^{5}$, Renato G.G. Terzi ${ }^{6}$, Desanka Dragosavac ${ }^{3}$, \\ Ana Paula Devite Cardoso ${ }^{5}$, Rosmari A.R.A. Oliveira7
}

\begin{abstract}
Introduction: Patients with severe brain lesions (SBL) and brain-dead patients (BD) frequently present with vasopressin (AVP) secretion disorders. Objective: To evaluateAVP serum levels in SBL and BD patients. Design: Prospective, open label, observational trial. Setting: A general teaching hospital. Method: Three groups of adult subjects (age $\geq 18 \mathrm{y}$ ) of both sexes were included in this study: control group: 29 healthy volunteers; SBL group: 17 patients with Glasgow Coma Scale (GCS) $\leq 8$; and BD group: 11 brain-dead patients. Samples of venous blood were collected in the morning at rest from healthy volunteers and at 8 hourly intervals over a period of $24 \mathrm{~h}$ from SBL and BD patients for AVP determinations. Concomitantly, some clinical and laboratorial variables were also recorded. Results: AVP serum levels (pg/ml) were [mean (SD); median]: control [2.2(1.1);2.0]; SBL [5.7(6.3); 2.9]; and $\mathrm{BD}[2.6(1.0) ; 2.8]$. AVP serum levels varied greatly in SBL patients, but without statistically significant difference in relation to the other groups $(p=0.06)$. Hypotension $(p=0.02)$, hypernatremia $(p=0.0001)$, serum hyperosmolarity $(p=0.0001)$ and urinary hypoosmolarity $(p=0.003)$ were outstanding in BD patients when compared with SBL. Conclusions: The AVP serum levels did not demonstrate significant statistical difference betw een the groups, only showing a greater variability in SBL patients (manifested as serum spike levels). Hypernatremia and hyperosmolarity were present in BD patients, indicating a failure of the hypothalamic-pituitary system in AVP production and release.
\end{abstract}

KEY WORDS: brain lesion, brain death, vasopressin.

\begin{abstract}
Níveis séricos de arginina vasopressina em pacientes com lesão cerebral grave e em pacientes com morte encefálica

RESUM 0 - Introdução: Pacientes com lesão cerebral grave (LCG) ou com morte encefálica (ME) freqüentemente apresentam alterações na secreção de vasopressina (AVP). Objetivo: Avaliar os níveis séricos de AVP em pacientes com LCG e ME. Desenho: Estudo prospectivo, aberto, observacional. Local: Um hospital geral universitário. M étodo: Sujeitos adultos (idade $\geq 18$ anos), de ambos os sexos, foram divididos em três grupos: grupo controle: 29 voluntários sadios; grupo LCG: 17 pacientes com pontuação na Escala de Coma de Glasgow (ECG) $\leq 8$; grupo ME: 11 pacientes com diagnóstico de ME. Amostras de sangue venoso foram colhidas pela manhã, em repouso, nos pacientes do grupo controle, e de 8/8h, por 24h, nos pacientes dos grupos LCG e ME, para dosagens de AVP. Variáveis clínicas e laboratoriais de interesse foram anotadas concomitantemente. Resultados: Os valores da AVP (pg/ml) foram [média (DP); mediana]: grupo controle [2,2(1,1);2,0]; grupo LCG $[5,7(6,3) ; 2,9]$ e grupo ME $[2,6(1,0) ; 2,8]$. Observouse maior variação dos níveis séricos de AVP no grupo $L C G$, mas sem diferença estatisticamente significativa em relação aos demais $(p=0,06)$. Hipotensão $(p=0,02)$, hipernatremia $(p=0,0001)$, hiperosmolaridade sérica $(p=0,0001)$ e hiposmolaridade urinária $(p=0,003)$ foram proeminentes no grupo ME em relação ao grupo LCG. Conclusão: Não foram encontradas diferenças estatisticamente significativas nos níveis de AVP entre os grupos, notando-se apenas uma maior variação de seus níveis séricos no grupo LCG (expressa sob a forma de picos séricos isolados). Hipernatremia e hiperosmolalidade estiveram presentes no grupo ME, indicando uma deficiência do sistema hipotálamo-hipofisário na produção e/ou liberação de AVP.
\end{abstract}

PALAVRAS-CHAVE: lesão cerebral, morte encefálica, vasopressina.

Department of Neurology, Faculty of Medical Sciences (FCM), State University of Campinas, Campinas SP Brazil (UNICAM P); Department of Surgery, FCM, UNICAMP; Department of Clinical Medicine, Ribeirão Preto Faculty of Medicine, University of São Paulo, Ribeirão Preto SP Brazil (FM RP-USP); and Intensive Care Unit, Hospital das Clínicas - UNICAMP (ICU-HC-UNICAMP): 'Doctoral student, Department of Neurology, FCM-UNICAMP; ${ }^{2}$ Associate Professor, Department of Neurology, FCM -UNICAM P; ${ }^{3}$ sssistant Professor, PhD, Department of Surgery, FCM -UNICAM P; ${ }^{4}$ Associate Professor, Department of Clinical M edicine, FM RP-USP; ${ }^{5}$ Assistant Physician, ICU-HC-UNICAM P; ${ }^{6}$ Titular Professor, Department of Surgery, FCM -UNICAM P; ${ }^{7}$ M aster's student, Department of Surgery, FCM -UNICAM P.

Received 14 July 2003, received in final form 29 September 2003. Accepted 8 November 2003.

Dra. Eliane de Araújo Cintra - Rua Monte Aprazível 885/13 - 13092-640 Campinas SP - Brasil. E-mail: eliane.cintra@bol.com.br 
Arginine-vasopressin (AVP) is an octapeptide hormone synthesized in the magnocellular neurons of the hypothalamic supraoptic and paraventricular nuclei. The granules containing AVP are axonally transported to the posterior pituitary, where they are stored. This hormone is released into the blood stream when plasmatic osmolarity rises or as a result of a baroreflex response to hypovolemia or reduced blood pressure ${ }^{1,2}$.

Neuroendocrinal, metabolic and hemodynamic changes involved in brain death (BD) have been intensively investigated and many studies have reported reduced circulating levels of the hormone in the anterior and posterior hypophysis ${ }^{3-6}$. Failure of the posterior hypophysis is clinically manifested as diabetes insipidus (DI) ${ }^{7}$.

Patients with severe brain lesions (SBL) such as head injury (HI), hemorrhagic cerebrovascular-accident (HCVA), ischemic cerebrovascular-accident (ICVA), subaracnoid hemorrhage $(\mathrm{SAH})$ without brain-death (BD), frequently present with AVP secretion disorders. However, these disorders still need to be clarified 8 .9.

Currently, no consensus has been found in the literature regarding the behavior of AVP in patients with SBL and in those with brain death. Therefore, the mean objective of this study was to evaluate AVP serum levels in SBL [Glasgow Coma Score $(G C S) \leq 8$ ] and brain-dead patients, and concomitantly verify their correlation with some clinical and laboratory variables.

\section{METHOD}

This study was approved by our institutional Research Ethics Committee under document number 062/98. Written informed consents were obtained from a family member or from individuals legally responsible for the patients, and, in the case of the control group, they were signed by the volunteers themselves.

The study was conducted in the Adult Intensive Care Unit, Neurology Unit, Neurosurgical Unit and Emergency Room at the Hospital das Clínicas (HC-UNICAM P), from November 1998 to January 2000 , and was composed of three groups, as following.

Control group (CTRL) - 29 healthy adult volunteers, age $\geq 18$ years, both sexes. Venous blood samples $(10 \mathrm{ml})$ were drawn in the morning, before breakfast, to determine the AVP, electrolytes, glucose and osmolarity serum levels.

Severe brain lesion group (SBL) - 17 patients with severe brain lesions (GCS $\leq 8$ ), age $\geq 18$ years and of both sexes, including four patients with HCVA, two with SAH and 11 patients with HI. All of them have a hospitalization period $\leq 48$ hours. Venous blood samples $(10 \mathrm{ml}$ ) were collected every 8 hours for 24 hours to determine serum AVP and serum osmolarity levels. Urine samples were also collected to determine the osmolarity. Concomitantly, hemodynamic variables [heart rate, systemic arterial blood pressure (SABP) and central venous pressure] and vasoactive drugs (type and dosage), sedatives, osmotic diuretics and/or loop diuretics being used were also recorded. In this group, exclusion criteria were defined as: patients aging $<18$ years and those with associated multiple trauma, sepsis, multiple organ dysfunction syndrome (M ODS), refractory shock and clinical signs of pregnancy.

Brain death group (BD) - 11 patients of both sexes, age $\geq 18$ years and with a confirmed diagnosis of brain death in accordance with the norms set by the Federal Council of M edicine, Ministry of Health, Brazil, edict number 1480/97. The procedures conducted in the SBL group were also applied to this group. The criteria for exclusion were: BD due to post-anoxia lesion, sepsis, multiple organ failure, refractory shock and pregnancy.

Arterial blood samples were collected from patients in the SBL and $B D$ groups for the analysis of gases, electrolytes, hemoglobin, hematocrit and lactate (RADIOM ETER-ABL-700 SERIES ${ }^{R}$ ). Additional venous blood samples were referred to specific laboratories for urea and creatinine dosage as well as for white cell count. The radioimmunoassay technique was used to determine AVP serum levels according to Moreira ${ }^{10}$, at the Laboratory of Endocrine Physiology, Faculty of M edicine, Ribeirão Preto, University of São Paulo, USP.

Statistical analysis: Chi-square test or Fisher's Exact Test, whenever required, were applied to compare categorical variables among the three groups. The Kruskal-Wallis non-parametric test was used to compare continuous variables. However, some variables were recorded only for the SBL and BD groups and, in this case, the M annWhitney test was applied to calculate the $p$-value. Correlations between some variables of interest in the SBL group were verified using the Spearman's rank correlation coefficient. The analysis was conducted using $n$ as the number of patients or the number of samples collected. A probabilistic $p$-value $<0.05$ was considered significant.

\section{RESULTS}

AVP serum levels - AVP was detected in all the patients and presented similar values in the CTRL and BD groups. The AVP serum levels in the SBL group demonstrated greater variability, manifested as isolated serum spike levels, but without any statistically significant difference among the three groups

Table 1. AVP serum levels in control (CTRL), severe brain lesion (SBL) and braindead (BD) groups; $n=$ number of patients.

\begin{tabular}{lcccccccc}
\hline Variable & Group & $n$ & Mean & (SD) & Max & Med & Min & p-value \\
\hline AVP & CTRL & 29 & 2.22 & $(1.15)$ & 5.20 & 2.00 & 0.4 & \\
$(\mathrm{pg} / \mathrm{ml})$ & SBL & 17 & 5.66 & $(6.26)$ & 23.20 & 2.88 & 0.9 & 0.0596 \\
& BD & 11 & 2.61 & $(1.0)$ & 4.25 & 2.82 & 0.65 & \\
\hline
\end{tabular}

AVP, arginine-vasopressin; SD, standard deviation; Max, maximum value; M ed, median value; $M$ in, minimum value. 
Table 2. Hemodynamic variables and the use of noradrenalin (NOR) in the severe brain lesion (SBL) and brain-dead (BD) groups, $n=$ number of samples.

\begin{tabular}{lcccccccc}
\hline Variable & Group & $n$ & Mean & (SD) & Max & Med & Min & p-value \\
\hline SAP & SBL & 72 & 132.4 & $(25.7)$ & 250 & 129 & 95 & 0.0087 \\
$(\mathrm{mmHg})$ & $\mathrm{BD}$ & 36 & 112.1 & $(33.4)$ & 163 & 115 & 40 & \\
& & & & & & & & \\
DAP & SBL & 72 & 77.1 & $(18.2)$ & 140 & 73 & 45 & 0.0723 \\
$(\mathrm{mmHg})$ & $\mathrm{BD}$ & 36 & 67.2 & $(19.9)$ & 101 & 71 & 20 & \\
& & & & & & & & \\
MAP & SBL & 72 & 97.5 & $(19.9)$ & 177 & 93 & 52 & 0.0030 \\
$(\mathrm{mmHg})$ & $\mathrm{BD}$ & 36 & 81.0 & $(24.9)$ & 126 & 84 & 14 & \\
& & & & & & & & \\
NOR & SBL & 18 & 0.24 & $(0.17)$ & 0.6 & 0.22 & 0.03 & 0.0486 \\
$(\mu \mathrm{g} / \mathrm{kg} / \mathrm{min})$ & $\mathrm{BD}$ & 32 & 0.47 & $(0.50)$ & 2.0 & 0.36 & 0.02 & \\
\hline
\end{tabular}

SAP, systolic arterial pressure; DAP, diastolic arterial pressure; M AP, mean arterial pressure; Max, maximum value; M ed, median value; $M$ in, minimum value.

$(p=0.0596)$ (Table 1$)$.

Hemodynamic variables and the use of noradrenalin Systolic and mean arterial pressures in BD group were significantly lower than those in the SBL group $(p=0.0087$ and $p$ $=0.030$, respectively). The patients in both groups (SBL and $\mathrm{BD}$ ) needed to use noradrenalin (NOR) at some time, with $\mathrm{BD}$ patients showing a greater tendency and a need for higher doses $(p=0.0486)$ (Table 2).

Respiratory and hemometabolic - Variables: when the BD and SBL groups were compared, statistically significant differences were found in relation to the $F_{1} O_{2}$ values $(B D>S B L ; P=$ 0.0003 ) and $\mathrm{PaO}_{2} / F_{1} \mathrm{O}_{2}$ values $(\mathrm{BD}<\mathrm{SBL} ; \mathrm{P}=0.0097)$. Metabolic acidosis and higher levels of serum lactate were more often observed in the BD group than in the SBL group $(p=0.0003$ and $p=0.0001$, respectively). Abnormal high levels of blood glucose were frequently seen in the SBL and BD groups when compared to the CTRL group, with statistically significant differences (BD > SBL > CTRL; $p=0.0001$ ) (Table 3).

Serum electrolytes, serum osmolarity and urinary osmolarity - Potassium and sodium serum levels were significantly higher in the BD group than in the SBL and CTRL ones $(p=$ 0.0002 and $p=0.0001$, respectively). Serum osmolarity was significantly higher in the BD group when compared with the CTRL and SBL groups $(p=0.0001)$. Urinary osmolarity was greatly reduced in the $B D$ group when compared with the SBL group $(p=0.0030)$ (Table 4$)$.

Correlations between AVP, osmolarity and serum sodium in the $S B L$ group - In the $S B L$ group negative correlations were found between serum osmolarity and AVP levels $(r=$ $0.27141 ; p=0.0211$ ) (Fig 1 ) and between serum sodium and AVP levels ( $r=-0.27829 ; p=0.0179)$ (Fig 2).

\section{DISCUSSION}

Generally, the basal AVP serum levels in normal individuals, at rest, have been found to be very low. Chen et al. ${ }^{11}$ have reported that the AVP serum levels in normovolemic and normotense individuals, with plasmatic osmolarity $\leq 290 \mathrm{mOsm} / \mathrm{L}$, ranged between 2.2 and $8.0 \mathrm{pg} / \mathrm{ml}$. In a study that has assessed endocrine failure after BD, Gramm et al. ${ }^{16}$ utilized AVP serum levels between 0.3 and $4.7 \mathrm{pg} / \mathrm{ml}$ as reference. In the present study, the AVP serum levels in normal individuals (control group) were also low $(0.4$ to $5.2 \mathrm{pg} / \mathrm{ml})$ and did not differ from the values recorded in BD patients $(0.6$ to $4.2 \mathrm{pg} / \mathrm{ml})$, which meant that the dosage of this hormone alone does not have the sensitivity or specificity to help in the diagnosis of BD. Therefore, serum AVP measurement in clinical situations is of interest only when an elevation is expected or when a provocative test have to be performed.

The AVP serum levels demonstrated a greater variability in the SBL group, manifested as isolated circulatory spikes release. However, statistically significant differences were not found among the three groups $(p=0.0596)$.

The regulator mechanisms of the AVP secretion include effective changes in arterial pressure and/or blood volume and serum osmolarity. Differently from osmolarity mechanism, hemodynamic derangements acts vary rapidly and in an exponential way on AVP release. Hence, small falls in arterial pressure or circulating blood volume ( 5 to $10 \%$ ) would have a very small effect on this secretion. How ever, large alterations (20 to $30 \%$ ) may increase the normal circulating levels of vasopressin 20 to 30 fold, exceeding the concentration needed to induce maximum antidiuresis ${ }^{1,2,13}$.

Brain death results in the total loss of the central regulatory mechanism of hemodynamic stability, even in the case of patients on adequate ventilatory support, hydroelectrolytic 
Table 3. Respiratory and hemometabolic variables in the control (CTRL), severe brain lesion (SBL) and brain-dead (BD) groups; $n=$ number of patients.

\begin{tabular}{|c|c|c|c|c|c|c|c|c|}
\hline Variable & Group & $n$ & Mean & (SD) & Max & Med & Min & $p$-value \\
\hline \multirow[t]{2}{*}{$\mathrm{F}_{1} \mathrm{O}_{2}$} & $\mathrm{SBL}$ & 17 & 0.49 & $(0.11)$ & 0.77 & 0.45 & 0.40 & 0.0003 \\
\hline & $\mathrm{BD}$ & 11 & 0.82 & $(0.22)$ & 1.0 & 0.92 & 0.45 & \\
\hline \multirow[t]{2}{*}{$\mathrm{pH}$} & $\mathrm{SBL}$ & 17 & 7.45 & $(0.05)$ & 7.52 & 7.46 & 7.31 & 0.0003 \\
\hline & $B D$ & 11 & 7.32 & $(0.10)$ & 7.44 & 7.36 & 7.16 & \\
\hline $\mathrm{PaO}_{2}$ & SB & 17 & 128.2 & $(35.5)$ & 212 & 121 & 89 & 0.6381 \\
\hline$(\mathrm{mmHg})$ & $\mathrm{BD}$ & 11 & 133.1 & (73.6) & 281 & 106 & 44 & \\
\hline $\mathrm{PaCO}_{2}$ & $\mathrm{SBL}$ & 17 & 31.2 & (5.5) & 44 & 31 & 22 & 0.3232 \\
\hline$(\mathrm{mmHg})$ & $\mathrm{BD}$ & 11 & 33.7 & $(6.1)$ & 44 & 34 & 25 & \\
\hline $\mathrm{HCO}_{3}$ & $\mathrm{SBL}$ & 17 & 21.4 & $(2.7)$ & 26 & 22 & 15 & 0.0073 \\
\hline (mEq/L) & $B D$ & 11 & 18.3 & $(2.6)$ & 24 & 18 & 14 & \\
\hline $\mathrm{BE}$ & $\mathrm{SBL}$ & 17 & -1.4 & $(2.6)$ & 1.9 & -0.5 & -7.9 & 0.0002 \\
\hline$(\mathrm{mEq} / \mathrm{L})$ & $B D$ & 11 & -6.7 & $(2.5)$ & -1.1 & -6.7 & -10.7 & \\
\hline $\mathrm{SaO}_{2}$ & SBL & 17 & 97.7 & $(0.9)$ & 99 & 98 & 96 & 0.1097 \\
\hline$(\%)$ & $\mathrm{BD}$ & 11 & 95.1 & $(5.0)$ & 99 & 97 & 82 & \\
\hline $\mathrm{PaO}_{2} / \mathrm{FiO}_{2}$ & $\mathrm{SBL}$ & 17 & 276.8 & $(94.6)$ & 438 & 267 & 152 & 0.0097 \\
\hline$(\mathrm{mmHg})$ & $B D$ & 11 & 174.2 & $(90.0)$ & 357 & 139 & 80 & \\
\hline Glycemia & CTRL & 29 & 87.4 & $(7.6)$ & 105 & 86 & 73 & 0.0001 \\
\hline \multirow[t]{2}{*}{$(\mathrm{mg} \%)$} & $\mathrm{SBL}$ & 17 & 162.4 & $(51.9)$ & 257 & 143 & 115 & \\
\hline & $\mathrm{BD}$ & 11 & 245.1 & $(85.5)$ & 442 & 219 & 140 & \\
\hline Lactate & CTRL & 29 & 1.22 & $(0.33)$ & 1.8 & 1.1 & 0.7 & 0.0001 \\
\hline \multirow[t]{2}{*}{ (mMol/L) } & SBL & 17 & 2.03 & $(0.74)$ & 3.2 & 2.1 & 0.9 & \\
\hline & $\mathrm{BD}$ & 11 & 2.92 & $(0.64)$ & 4.0 & 2.7 & 2.0 & \\
\hline
\end{tabular}

Max, maximum value; Med, median value; M in, minimum value; SD, standard deviation.

Table 4. Values of serum electrolytes, serum osmolarity and urinary osmolarity in the control (CTRL), severe brain lesion (SBL) and brain-dead (BD) groups; $n=$ number of patients.

\begin{tabular}{lcccccccc}
\hline Variable & Group & $n$ & Mean & (SD) & Max & Med & Min & p-value \\
\hline Serum Na & CTRL & 29 & 138.2 & $(2.4)$ & 141 & 138 & 131 & 0.0001 \\
(mEq/L) & SBL & 17 & 137.9 & $(5.9)$ & 154 & 137 & 129 & 138 \\
& BD & 11 & 152.4 & $(8.4)$ & 169 & 152 & & \\
& & & & & & & & \\
Serum K+ & CTRL & 29 & 3.72 & $(0.20)$ & 4.1 & 3.7 & 3.3 & 3.0002 \\
(mEq/L) & SBL & 17 & 3.88 & $(0.31)$ & 4.5 & 3.9 & 3.4 & \\
& BD & 11 & 4.37 & $(0.52)$ & 5.5 & 4.4 & 3.6 & \\
OsmSer & CTR & 29 & 278.6 & $(7.2)$ & 300 & 279 & 268 & 0.0001 \\
(m0sm/L) & SBL & 17 & 285.2 & $(14.3)$ & 324 & 284 & 263 & \\
& BD & 11 & 317.3 & $(17.3)$ & 348 & 313 & 290 & \\
OsmÚr & SBL & 17 & 439.8 & $(119.6)$ & 711 & 422 & 285 & 0.0030 \\
(m0sm/L) & BD & 11 & 256.6 & $(30.6)$ & 443 & 239 & 86 & \\
\hline
\end{tabular}

Max, maximum value; Med, median value; $M$ in, minimum value; OsmSer, serum osmolarity; OsmUr, urinary osmolarity. 


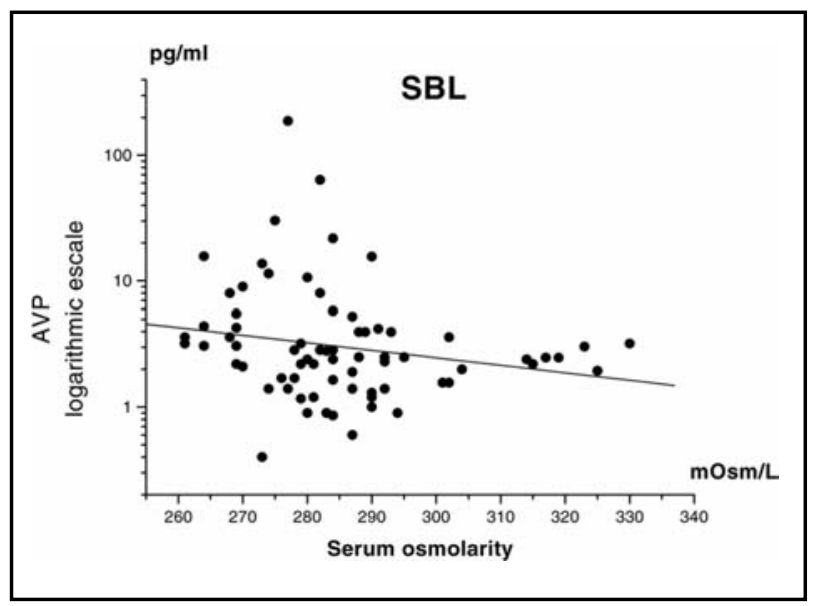

Fig 1. Negative correlation between osmolarity and AVP serum levels in the severe brain lesion (SBL) group; $n=$ number of samples $(n=72 ; r=-0,27141$; $p=0,0211$.

and acid-base balance correction, and maximum conventional pharmacological support of the circulation ${ }^{3-6,14,15}$. In this study, the BD group demonstrated lower mean AP levels when compared with the SBL group and did not present a rapid increase in the AVP circulating levels in response to this hypotension, as was normally expected in such circumstance ${ }^{1,2,213}$.

In brain-dead patients, this fact can be explained by the alterations that occur in the synthesis and/or release of AVP in the hypothalamus, as underscored by How llet et al. ${ }^{16}$. However, the AVP serum levels could always be detected in these patients and the values were similar to those of normal individuals. Sugimoto et al. ${ }^{17}$ tried to clarify this finding in a study conducted on 28 brain-dead patients. They assessed the morphological and functional alterations of the hypothalamus and posterior pituitary in 12 of these patients. Microscopic alterations in the hypothalamus could only be assessed in four cases due to extensive cerebral necrosis and lack of adequate material for microscopy. An analysis of this material revealed that the nerve tissue was totally necrotic, with edematous cells, loose of the nucleus, and not a single positive vasopressin granule was present. The authors, therefore, reached the conclusion that AVP synthesis was totally affected by BD. Nevertheless, a microscopic analysis of the posterior pituitary lobe revealed hardly any alteration. Positive vasopressin granules were observed in the posterior lobe and in the infundibular stem of all the specimens, which in some cases continued for up to 20 days after $\mathrm{BD}^{17}$, and this could explain explains the fact that serum AVP remained detectable in these patients.

The brain is considered the main site for vasopressin synthesis ${ }^{1,2,13}$. However, a small production of AVP has been reported in endocrinal tissues, including the ovaries and testicles, and in the endothelial cells of the lungs, kidneys and mesenteric arteries ${ }^{18}$. Hupf et al. ${ }^{19}$ also identified in rats' heart a system that synthesized and release AVP into the blood stream.

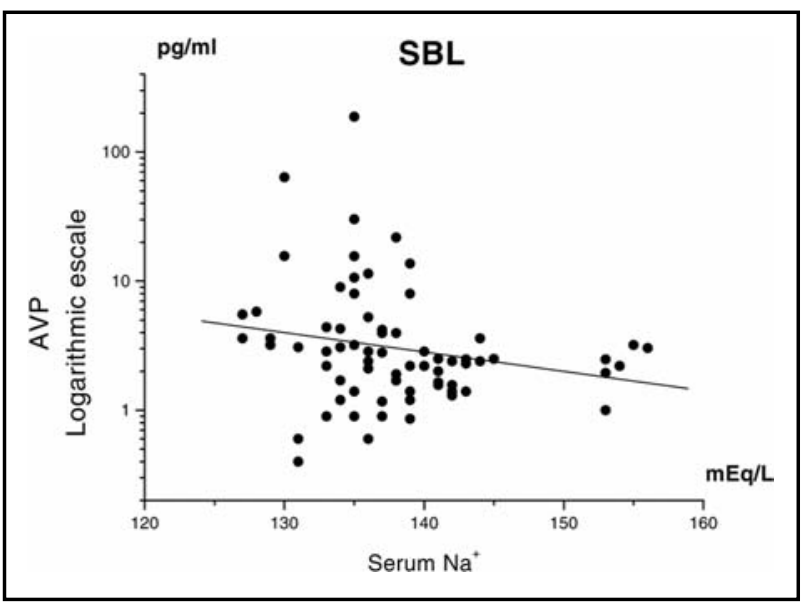

Fig 2. Negative correlation between serum sodium $(\mathrm{Na}+)$ and AVP serum levels in the severe brain lesion (SBL) group; $n=$ number of samples $(n=72 ; r$ $=-0,27829 ; p=0,0179$ ).

The profound alterations observed in hemodynamic, respiratory and hemometabolic parameters revealed clear homeostasis deterioration in the BD group when compared with the SBL group, and this fact is in accordance with literature reports ${ }^{20,21}$.

There were also evidences in patients who evolved to brain death indicating that cellular metabolism was abnormal, regardless of cardiac output and microvascular auto-regulation, as a result of endocrinal abnormalities secondary to loss of the hypothalamic function $11,12,14,16$. This polyhormonal deficit could induce a generalized metabolic hypoxic lesion that also contributes towards the inability to maintain the acid-base balance 22,23 .

In the present study, blood glucose levels were found to be substantially higher in the BD group than in SBL, which could be due to the rapid infusion of enriched glucose solutions utilized for fluid and electrolyte replacement and to the presence of an endocrinal failure, Indeed, many authors ${ }^{4,5,24}$ have confirmed that endocrinal failure actually occurs in BD, and that hormonal replacement is necessary to retard hole body cell death. Novitzky et al. ${ }^{5}$ and Mariot et al. ${ }^{25}$ recorded a significant reduction in some hormones, mainly free triodotyronine, cortisol and insulin, in brain dead patients.

Patients in BD group presented with elevated serum osmolarity and reduced urinary osmolarity, associated, however, with low serum levels of AVP, indicating that one of the most important AVP secretion stimulus ${ }^{1,2,13}$ had failed in this group. In a study conducted on brain-dead children, Fiser et al. ${ }^{26}$ had already observed $38 \%$ diabetes insipidus. Other authors ${ }^{7}$ also found DI in 14 out of 16 children who fulfilled the criteria for brain death, and inferred that the occurrence of DI after ischemic or hypoxic insult could represent the mesencephalic neuron cell death.

In the present study, a statistically significant negative 
correlation was found between serum osmolarity and serum sodium with AVP levels in the SBL group. Theoretically, a reduction in serum osmolarity, as normally seen in hypotonic fluid overload test, tends to reduce AVP secretion ${ }^{27}$, i.e., the correlation is positive. The negative correlation found in this study suggests inappropriate AVP secretion (Syndrome of Inappropriate Antidiuretic Hormone Secretion - SIADH). Kamoi et al. ${ }^{8}$ observed this syndrome in patients with CNS disorders: subdural hematomas, closed head injury, epilepsy and ischemic cerebrovascular accident. Patients with SIADH and CNS disorders may present persistent AVP secretion with loss of hypotonic suppression, indicating that a careful assessment is required to determine the relationship between persistent AVP secretion and the pathogenesis of hyponatremic disorders $^{8}$.

Lazló et al. ${ }^{28}$ recorded the frequency of the clinical characteristics, laboratory alterations and diagnostic criteria of SIADH in 290 patients with SAH. SIADH was diagnosed in 27 patients $(9.3 \%)$, and the authors suggest that vasoactive substances secreted after $\mathrm{SAH}$, mainly AVP, could play an important role in the development of cerebral edema ${ }^{28}$.

The literature underscores the fact that increased permeability of the brain capillaries is one of the most important mechanisms responsible for the outset and the maintenance of brain edema in patients with SAH, and probably AVP may directly affect cerebral microcirculation by activating the nucleotide system with a second messenger system ${ }^{29}$. M oreover, the central effect of AVP may extend peripherically, for example, to the kidney, its most important target organ, where it may affect water retention ${ }^{30}$. Indeed, based on their findings and the data in the literature, Lazlo et al. ${ }^{28}$ put forth the hypothesis that an increase in the AVP levels during the early phases of SAH may be pathogenically important in the development of cerebral edema. AVP w ould release this effect through the $V_{2}$ receptors in a complex manner: increasing cerebral capillary permeability and inducing water retention, natriuresis and hypervolemia by its activity in the renal tubular function, promoting or aggravating cerebral edema in victims of $\mathrm{SAH}^{28}$.

In conclusion, the method utilized in this study helped verify that AVP serum levels in normal individuals, at rest, were very low, which was in accordance with the data reported in the literature. Although the AVP serum levels have shown a greater variability in the SBL group (manifested as isolated serum spike levels), they were not significantly different from the values obtained in the BD and control groups. Nonetheless, the finding of a negative correlation between AVP with serum osmolarity and serum sodium suggests the occurrence of SIADH in SBL group, warranting further studies. The clinical and laboratory data also revealed a general deterioration of organic functions in the BD group when compared with the SBL group.
The patients in the BD group presented hemodynamic, respiratory, metabolic, acid-base and hydroelectric dysfunctions, specially hypernatremia and hyperosmolarity, indicating a hypothalamus-pituitary failure in AVP production and release.

Acknowledgements - Our grateful thanks to Laurione Cândido de Oliveira, biologist at the Physiology Laboratory, HC-UNICAM P, for collaborating in the collection of material for AVP dosage; Airton Fernando de Paula, biologist at the Biochemistry Laboratory, HCUNICAMP, for collaborating in the measurement of urine and serum osmolarities; Lucimara Bueno and Adriana Rossi, Endocrinology Laboratory, HC-FM RP-USP, for collaborating in AVP dosage; and Helymar da Costa Machado, Research Commission, FCM-UNICAMP, for the statistical analysis of the data.

\section{REFERENCES}

1. Schrier RW, Berl T, Anderson RJ. Osmotic and nonosmotic control of vasopressin release. Am J Physiol 1979;236:321-332.

2. Share L. Role of vasopressin in cardiovascular regulation. Physiol Reviews 1988;68:1248-1284.

3. Soifer B, Gelb AW. The multiple organ donor: identification and management. Ann Intern Med 1989;110:814-823.

4. Novitzky D, Cooper DKC. Results of hormonal therapy in human brain-dead organ donors. Transplant Proc 1988;20(Suppl.7):S59-S62.

5. Novitzky D, Cooper DKC, Wicomb WN. Endocrine changes and metabolic responses. Transplant Proc 1988;20(Suppl.7):S33-S38.

6. Cooper DKC, Basker M. Physiologic changes following brain death. Transplant Proc 1999;31:1001-1002.

7. Outwater KM, Rockoff MA. Diabetes insipidus accompanying brain death in children. Neurology 1984;34:1243-1246.

8. Kamoi K, Toyama M, Takagi M, et al. Osmoregulation of vasopressin secretion in patients with the syndrome of inappropriate antidiuresis associated with central nervous system disorders. Endocr J 1999;46:269-277.

9. Qu F, He X, Lu W, Wang Y. Neurohypophysical AVP concentration in stroke patients. Chin Med J 1995;108:259-261.

10. Moreira AC. Radioimunoensaio da vasopressina: montagem e padronização. Arq Bras Endocrinol Metab 1995;39:54.

11. Chen EP, Bittner HB, Kendall SW, Van-Trigt P. Hormonal and hemodynamic changes in a validated animal model of brain death. Crit Care Med 1996;24:1352-1359.

12. Gramm HJ, Meinhold H, Bickel U, et al. Active endocrine failure after brain death? Transplantation 1992;54:851-857.

13. Robertson G. Regulation of vasopressin secretion. In: Seldin DW, Giebsch G (eds). The kidney: physiology and pathophysiology. 2.Ed, New York: Raven Press, 1992:1595-1613.

14. Novitzky D, Wicomb WN, Cooper DKC, Rose AG, Fraser RC, Barnard $\mathrm{CN}$. Electrocardiographic, hemodynamic, and endocrine changes occurring during experimental brain death in the Chacma baboon. J Heart Transplant 1984;4:63-69.

15. Cintra EA, Maciel JA Jr, Araújo S, Castro M, Martins EF. Vasopressina e morte encefálica. Arq Neuropsiquiatr 2000;58:181-187.

16. Howlett TA, Keog AM, Perry L, Touzel R, Reesl H. Anterior and posterior pituitary function in brain-stem-dead donors: a possible role for hormonal replacement therapy. Transplantation 1989;47:828-834.

17. Sugimoto T, Sakano T, Kinoshita Y, Massui M, Yoshioka T. Morphological and functional alterations of the hypothalamic-pituitary system in brain death with long term bodily living. Acta Neurochir (Wien) 1992;115:31-36.

18. Lincoln J, Loesch A, Burnstock G. Localization of vasopressin, serotonin, and angiotensin II in endothelial cells of the renal and mesenteric arteries of the rat. Cell Tissue Res 1990;259:341-344.

19. Hupf H, Grimm D, Riegger GA, Schunkert H. Evidence for vasopressin system in the rat heart. Circulation Res 1999;19:365-370.

20. Delmonico FL, Reese JC. Organ donor issues for the intensive care physician. J. Intensive Care Med 1998;13:269-278.

21. Nygaard CE, Townsend RN, Diamond DL. Organ donor management and outcome: a 6 years review from a level-1 trauma center. J Trauma 1990;30:728-732.

22. Araújo S, Cintra EA, Bachega EB. Manutenção do potencial doador. In Cintra EA, Nishida VM, Nunes WA (eds). Assistência de enfermagem 
ao paciente gravemente enfermo. 2.Ed, São Paulo: Atheneu, 2001:443-456.

23. Jonas M, Oduro A. Management of the multi-organ donor. In: Higgins RS, Sanches JA, Lorber MI, Baldwin JC (eds). The multiorgan donor selection and management. Malden: Blackwell Science, 1997:123-139.

24. Powner DJ, Hendrich A, Lagler RG, Ng RH, Madden RL. Hormonal changes in brain dead patients. Crit Care Med 1990;18:702-708.

25. Mariot J, Sadonic IO, Jacob F, et al. Hormone levels, hemodynamics, and metabolism in brain dead organ donors. Transplant Proc 1995;27:793-794.

26. Fiser DH, Jimenez JF, Wrape V, Woody R. Diabetes insipidus in children with brain death. Crit Care Med 1987;15:551-553.

27. Vokes TJ, Robertson GL. Disorders of antidiuretic hormone. Endocrinol Metabol Clin N Am 1988;17:281-299.

28. Laszló FA, Varga C, Doczi T. Cerebral oedema after subarachnoid haemorrhage. Pathogenetic significance of vasopressin. Acta Neurchir (Wien) 1995;133:122-133.

29. Rhipagen CL, Pittman QJ. Arginine vasopressin as a central neurotransmitter. Fed Proc 1986;45:2318-2322.

30. Morel F, Imbert-Teboul M, Chabardes D. Receptors to vasopressin and others hormones in the mammalian kidney. Kidney Int 1987;31:512-520. 